\title{
Os Desafios Da Saúde Suplementar E Da Proteção De Dados Pessoais À Luz Da LGPD Em Tempos De Pandemia
}

\author{
Denise Tanaka dos Santos * \\ Pontifícia Universidade Católica de São Paulo, Programa de Pós-Graduação em Direito, São Paulo-SP, \\ Brasil.
}

Resumo: O cenário de crise em tempos de eventos inesperados e de grande impacto social, como a Pandemia da COVID-19, demanda do direito tutelas jurídicas extraordinárias. Este trabalho pretende identificar o que há disponível no ordenamento jurídico nacional para o enfrentamento da questão, por intermédio de uma singela colaboração no avanço da pesquisa jurídica, com implicações na resolução desta questão emergente: os desafios da saúde suplementar e da proteção de dados pessoais à luz da LGPD em tempos de pandemia. O problema central será abordado de maneira sistemática, a partir de pesquisa bibliográfica. De início, concluiu-se que há no ordenamento jurídico robustos enunciados prescritivos axiológicos para a proteção de dados pessoais. Em seguida, apurou-se que a pandemia prorrogou o início da vigência da LGPD e, por fim, que o cenário atual da pandemia poderá, em alguma medida, ter antecipado a adoção de um plano de ação pelos atores da saúde suplementar para as adequações dos requisitos da LGPD.

Palavras-chave: LGPD. Pandemia da COVID-19. Proteção de dados pessoais. Saúde suplementar. Sociedade da informação.

* Doutora em Direito pela PUC-SP. Defensora Pública Federal. Conselheira Editorial da Revista da DPU. E-mail: dsan746@gmail.com

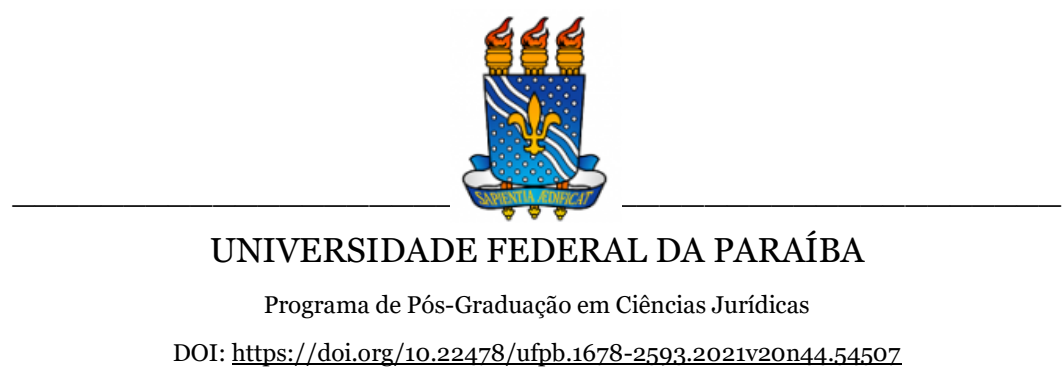

DOI: https://doi.org/10.22478/ufpb.1678-2593.2021v20n44.54507 


\title{
Os Desafios Da Saúde Suplementar E Da Proteção De Dados Pessoais À Luz Da LGPD Em Tempos De Pandemia
}

\author{
Denise Tanaka dos Santos
}

\section{INTRODUÇÃO}

O cenário de crise em tempos de eventos inesperados e de grande impacto social, como a pandemia do coronavírus SARS-CoV-2, causador da COVID-19, demanda do direito tutelas jurídicas extraordinárias. Segundo o pensamento de Ulrich Beck (2008, p. 8385), perante situações de risco global, faz-se necessário aplicar o princípio da previsão, mediante o qual se pode antecipar e evitar riscos, cuja existência não está provada. Convém ressaltar que entre esses riscos inseridos no princípio da previsão pode ser colocada a pandemia.

Importa salientar que este trabalho pretende identificar o que há disponível no ordenamento jurídico nacional e internacional, para regulamentar o uso de dados e de informações pessoais durante o período de pandemia. Através desta pesquisa jurídica, almeja-se avançar no debate sobre a seguinte questão emergente: os desafios da saúde suplementar e da proteção de dados pessoais à luz da Lei Geral de Proteção de Dados (LGPD), em tempos de pandemia. O problema central será abordado de maneira sistemática, a partir de pesquisa bibliográfica.

Para tanto, passou-se pela análise do cenário da pandemia decorrente da COVID-19; pelo exame da Lei de n. 13.709 (LGPD), publicada em 14 de agosto de 2018; pelo estudo sobre a proteção de dados pessoais em tempos de pandemia na sociedade da informação; e pelos fundamentos da proteção de dados pessoais. Ademais, 
Os Desafios Da Saúde Suplementar E Da Proteção De Dados Pessoais À Luz Da...

abordou-se o sistema jurídico de proteção na LGPD e a proteção de dados pessoais no cenário da pandemia; a saúde suplementar e a proteção de dados pessoais à luz da LGPD em tempos de pandemia e seus desafios.

Em virtude dessas considerações, foi possível concluir que há nos ordenamentos jurídicos nacional e internacional robustos enunciados prescritivos axiológicos para a proteção de dados pessoais, bem como que a pandemia prorrogou o início da vigência da LGPD e que o cenário atual da pandemia poderá, em alguma medida, ter antecipado a adoção de um Plano de Ação pelos atores da saúde suplementar para as adequações dos requisitos da LGPD.

\section{A PANDEMIA DO COVID-19}

Importa ressaltar que antes de analisar propriamente o panorama sobre a saúde suplementar e a proteção de dados pessoais à luz da LGPD, em tempos de pandemia, serão descritas, de forma breve, as circunstâncias históricas relacionadas à pandemia da COVID-19, decorrente do vírus Sars-Cov-2.

A Organização Mundial da Saúde (OMS), fundada em 1948, é uma agência especializada em saúde e subordinada à Organização das Nações Unidas (ONU). Sua origem remonta às guerras do final do século XIX, contudo, no final da Primeira Grande Guerra, a Liga das Nações criou o comitê de higiene que resultou como a semente da atual OMS.

Entre os objetivos da OMS estão o desenvolvimento do nível de saúde de todos os povos. A saúde é conceituada pela OMS, em sua Constituição, como um estado de completo bem-estar físico, mental e social, não somente da ausência de uma doença ou enfermidade.

Pois bem. A OMS, em 11 de março de 2020, declarou a pandemia da COVID-19 e mudou a classificação informada na 
primeira declaração, de 10 de janeiro de 2020. Com isso, os países foram obrigados a tomar atitudes preventivas.

Conforme declaração do diretor-geral da OMS, o etíope Tedros Adhanom, em março de 2020, a organização elevou o estado de contaminação à pandemia, não pela gravidade da doença COVID-19, mas pela rápida disseminação geográfica que o coronavírus tem apresentado, em uma escala de tempo muito curta, com níveis alarmantes de contaminação e com falta de ação dos governos (ONU, 2020).

Com as informações da OMS, os Estados, em nível global, passaram a tomar medidas preventivas e a promover ações governamentais com a finalidade de minimizar os efeitos da pandemia.

No Brasil, foi editada a Lei 13.979/20, de 6 de fevereiro de 2020, que dispõe sobre as medidas de enfrentamento da emergência de saúde pública de importância internacional, decorrente do coronavírus, responsável pelo surto de 2019. Na mesma linha, foi editado o Decreto Legislativo n. 6/20, de 20 de março de 2020, que, entre outras medidas extraordinárias e temporárias, reconheceu a ocorrência do estado de calamidade pública no Brasil.

A partir desses fatos mundiais, o cenário de saúde global se modificou. Como afirma Callejón (2020, p. 16-36), "vivemos com essa esperança, assumindo como provisórios novos hábitos e padrões de conduta exigidos pelas medidas de proteção à saúde”. Entre os efeitos da pandemia podem-se apontar alterações, entre outras, nas dimensões de saúde pública com relação à proteção da vida humana $\mathrm{e}$ nas dimensões sociais, com indicações econômicas de recessão, queda no PIB mundial, desemprego e falências. A ONU prevê, segundo relatório da Comissão Econômica das Nações Unidas para América Latina e Caribe (CEPAL), divulgado em Santiago do Chile, que as perdas são maiores do que as registradas durante a crise financeira de 2009 (CEPAL, 2020).

De maneira específica, os efeitos da pandemia repercutiram notadamente em três fatores emergenciais: o fator de crise econômica, 
Os Desafios Da Saúde Suplementar E Da Proteção De Dados Pessoais À Luz Da...

com repercussões desiguais e assimétricas; a perspectiva de emergência sanitária e a problemática da gestão pública de enfrentamento e de contenção do COVID-19.

Em consequência, todas as relações sociais podem restar modificadas em alguma medida, em especial na saúde suplementar e na proteção de dados pessoais à luz da LGPD, em tempos de pandemia. Diante disso, a Agência Nacional de Saúde (ANS) reforçou as orientações aos beneficiários de planos durante a pandemia.

Em verdade, é importante apontar que os problemas sociais, entre eles, a necessidade de regulamentação da proteção de dados pessoais nos contratos de saúde suplementar, já se encontravam dispostos no contexto da sociedade da informação, porém a pandemia pode ter potencializado exponencialmente essas questões.

A pandemia irradiou seus efeitos nas relações jurídicas em geral. O direito privado foi influenciado, tanto nas relações individuais, nos direitos sociais fundamentais, nas empresas, nos contratos, no direito do trabalho, quanto no comércio internacional, por exemplo, com o oportunismo na aquisição de equipamentos de saúde. Neste sentido, o diretor-geral da Organização Mundial do Comércio (OMC), Roberto Azevedo, reconhece que o comportamento mais agressivo de países na disputa por equipamentos médicos durante a pandemia pode prejudicar o futuro do comércio internacional (CNN, 2020).

Contudo, ainda que haja a emergência de providências em praticamente todas as ramificações do direito, é importante notar que o limite do princípio da legalidade constitucional determina, para a sociedade democrática e para o Estado Democrático de Direito, a obediência irrestrita às controvérsias decorrentes da pandemia para sair da crise sem sair da democracia, como afirma o Ministro do Supremo Tribunal Federal brasileiro Edson Fachin, em palestra ministrada na Pontifícia Universidade Católica do Paraná, em 2020. Em outros termos, corrigir disfunções dos Estados, dos Poderes e da sociedade sem sair da legalidade constitucional. 


\section{A LGPD E A PROTEÇÃO DE DADOS PESSOAIS EM TEMPOS DE PANDEMIA}

Após a sucinta abordagem sobre o cenário da COVID-19 no Brasil e no mundo, passa-se ao estudo da saúde suplementar e da proteção de dados pessoais à luz da LGPD em tempos de pandemia.

\subsection{A LGPD e a sociedade da informação}

Oportuno se torna dizer que a Lei Geral de Proteção de Dados Pessoais está inserida no contexto da sociedade da informação. De forma breve, sob o ponto de vista histórico da sociedade informacional, pode-se apontar um início agrícola das organizações de pessoas em sociedade. Já em um momento posterior, com a organização social, surgiram revoluções que transformaram as sociedades, em determinados períodos históricos.

Entre essas revoluções há que se apontar a revolução industrial, com o advento das máquinas a vapor e da eletricidade, no século XIX, e a revolução tecnológica, com a importância do conhecimento e da informação, no século XX.

A chamada sociedade da informação aborda os temas ligados à revolução tecnológica ou digital das redes mundiais de computadores, os quais impactaram a vida da humanidade, trazendo novos horizontes, com novos vocabulários, inovações, armazenamento de dados, propriedade intelectual.

Trata-se do novo petróleo, da nova propriedade, do novo poder que influencia todas as áreas do conhecimento, segundo dados apresentados no Fórum Econômico Mundial, em Davos, no ano de 2011 (WEF, 2011). A Comissária europeia, Meglena Kuneva, antecipou em discurso sobre tratamento de dados, em Bruxelas, Bélgica, ainda em 2009, que os dados pessoais são o novo óleo da Internet e a nova moeda do mundo digital (COMMISSION EUROPÉENNE, 2009).

Ocorre que, diferentemente das antigas revoluções, esta revolução tecnológica se altera de forma exponencial, em uma 
Os Desafios Da Saúde Suplementar E Da Proteção De Dados Pessoais À Luz Da...

velocidade nunca vista antes pela humanidade. Disso culminou a quarta revolução tecnológica da informação e da biotecnologia, com análise da nanotecnologia, da dimensão 3D, do computador quântico, da internet das coisas, do algoritmo, da inteligência artificial, do Bigdata, entre tantos outros.

Todas essas transformações repercutiram nas relações sociais e no direito. Assim, as questões decorrentes das modificações da sociedade da informação, no que se refere à saúde suplementar e à proteção de dados pessoais à luz da LGPD em tempos de pandemia, não são novas, mas podem ser impactadas pela pandemia.

\subsection{A LGPD e os fundamentos da proteção de dados pessoais.}

A Sociedade da Informação, a nova era tecnológica e digital, se transformou de forma exponencial, em uma velocidade nunca vista antes pela humanidade. Em verdade, todo esse quadro axiológicofático-normativo já causava ruídos nos ordenamentos jurídicos e na ciência do direito ao redor do planeta.

Visando estudar sobre a saúde suplementar e a proteção de dados pessoais em tempos de pandemia, neste quadro serão abordados os fundamentos normativos sobre a proteção de dados na Lei n. 13.709, de 14 de agosto de 2018, a Lei Geral de Proteção de Dados Pessoais (LGPD), com o início de vigência parcial postergado devido à pandemia.

A Lei Geral de Proteção de Dados Pessoais dispõe sobre o tratamento de dados pessoais, inclusive nos meios digitais, por pessoa natural ou por pessoa jurídica de direito público ou privado, com o objetivo de proteger os direitos fundamentais de liberdade e de privacidade e o livre desenvolvimento da personalidade da pessoa natural, bem como altera o Marco Civil da Internet (Lei 12.965/14), que regulou o uso da Internet no Brasil, por meio da previsão de princípios, garantias, direitos e deveres para quem usa a rede e para o Estado. 
A edição da LGPD permitiu ao Brasil ingressar entre os países que adotam legislações específicas de proteção de dados de seus cidadãos. A União Europeia inovou com o Regulamento Geral sobre a Proteção de Dados (RGPD), General Data Protection Regulation GDPR, em vigor desde 25 de maio de 2018. Na mesma linha, o Estado da Califórnia aprovou, em 2018, o California Consumer Privacy Act. Assim, com a adoção da legislação protetiva de dados pessoais, alinhada às Diretrizes da Organização para a Cooperação e Desenvolvimento Econômico (OCDE) de proteção de privacidade e de fluxo informacional de dados pessoais, o Brasil pode ingressar na OCDE.

A Lei 13.709, de 14 de agosto de 2018, também previu a criação, sem aumento de despesa, da Autoridade Nacional de Proteção de Dados (ANPD), órgão da administração pública federal, integrante da Presidência da República. Compete primordialmente à ANPD: zelar pela proteção dos dados pessoais, nos termos da legislação, fiscalizar e aplicar penalidades. A MP 869, de 27 de dezembro de 2018, determinou a criação da ANPD e alterou a vigência da LGPD para agosto de 2020. Destaque-se que a criação desse órgão será importante para o cumprimento efetivo da proteção de dados pessoais.

Cumpre assinalar que os fundamentos legais para a proteção e o uso de dados pessoais correspondem às determinações constitucionais brasileiras sobre os direitos e as garantias fundamentais da pessoa humana, os quais se alinham aos termos da Declaração Universal de Direitos Humanos, de 1948, art. XII: "ninguém será sujeito à interferência em sua vida privada, em sua família, em seu lar ou em sua correspondência, nem a ataque à sua honra e reputação. Todo ser humano tem direito à proteção da lei contra interferências ou ataques".

Ademais, a proteção de dados pessoais foi consagrada como direito fundamental na Carta de Direitos Fundamentais da União Europeia, de 2000, no art. $8^{\circ}$ : 
Proteção de dados pessoais: 1. Todas as pessoas têm direito à proteção dos dados de caráter pessoal que lhes digam respeito. 2. Esses dados devem ser objeto de um tratamento leal, para fins específicos e com o consentimento da pessoa interessada ou com outro fundamento legítimo previsto por lei. Todas as pessoas têm o direito de aceder aos dados coligidos que lhes digam respeito e de obter a respectiva retificação. 3. O cumprimento destas regras fica sujeito a fiscalização por parte de uma autoridade independente (JORNAL OFICIAL DAS COMINIDADES EUROPEIAS, 2000).

O Senado Federal brasileiro aprovou o encaminhamento de proposta de emenda constitucional, a PEC 17/2109, estabelecendo a proteção de dados como direito fundamental, com a modificação do inciso XII do art. $5^{\circ}$ da Carta de 1988, sendo inviolável o sigilo de correspondência e de comunicações telegráficas, de dados e comunicações telefônicas.

Nessa toada, a Lei Geral de Proteção de Dados Pessoais (LGPD) contempla fundamentos que devem ser observados nas relações sociais desta chamada Sociedade da Informação, no que se refere à proteção de dados pessoais, entre eles: a) o respeito à privacidade; b) a autodeterminação informativa; c) a liberdade de expressão, de informação, de comunicação e de opinião; d) a inviolabilidade da intimidade, da honra e da imagem; e) o desenvolvimento econômico e tecnológico e a inovação; f) a livre iniciativa, a livre concorrência e a defesa do consumidor; e, g) os direitos humanos, o livre desenvolvimento da personalidade, a dignidade e o exercício da cidadania pelas pessoas naturais.

Cumpre assinalar que os fundamentos da LGPD correspondem aos valores constitucionais que estão dispostos por toda a Carta de 1988 e que representam os valores supremos da sociedade, portanto desta Sociedade da Informação. A análise dos valores é importante, pois aborda as diretrizes a serem perseguidas pelo direito e pela ciência jurídica.

Nesse sentido, Paul Roubier (1951, p. 317-318) assevera que os valores são elementos axiológicos jurídicos: cette donnée fondamentale que le droit est une discipline normative et non point explicative. Il ne tend pas à formuler des jugements d'existence base 
sur le príncipe de causalité, mais des jugements de valeur fondés sur l'idée d'une finalité ${ }^{1}$.

Os valores constitucionais estão positivados por todo o texto da Constituição Federal de 1988 e são espécies normativas que fazem parte do direito como disciplina normativa, formulando julgamentos de valor fundados na ideia de finalidade.

Nesse sentido, o conceito de Canotilho (1993, passim) sobre Constituição como estatuto jurídico do político. Vale lembrar que, neste mundo globalizado, pode-se pensar sobre o ser político não só no espaço institucional do Estado, mas também no espaço da sociedade, da sociedade da informação.

O estudo dos valores constitucionais inicia-se no preâmbulo da Carta Política de 1988, com destaque aos valores da liberdade, da segurança, do bem-estar, do desenvolvimento, da igualdade e da justiça.

Wagner Balera (2004, p. 16) ensina que no preâmbulo das leis, os valores estão elencados como axiomas. São vetores com função interpretativa que conduzem o tema para um único campo exegético.

Assim, os valores constitucionais servem de guia exegético para a construção sistemática do direito à proteção de dados pessoais, no ambiente da Lei Geral de Proteção de Dados Pessoais para a saúde complementar.

A partir dessa análise, alinham-se alguns conceitos trazidos pela Lei n. $13.709 / 18$, constantes no art. $5^{\circ}$, entre eles: a) dado pessoal: informação relacionada a pessoa natural identificada ou identificável; b) dado pessoal sensível: dado pessoal sobre origem racial ou étnica, convicção religiosa, opinião política, filiação a sindicato ou a organização de caráter religioso, filosófico ou político, dado referente à saúde ou à vida sexual, dado genético ou biométrico, quando vinculado a uma pessoa natural; c) banco de dados: conjunto

\footnotetext{
${ }^{1}$ Tradução livre: Este fato fundamental de que o direito é uma disciplina normativa e não explicativa. Ele não tende a fazer julgamentos de existência baseados no princípio da causalidade, mas julgamentos de valor baseados na ideia de uma finalidade.
} 
estruturado de dados pessoais, estabelecido em um ou em vários locais, em suporte eletrônico ou físico; d) titular: pessoa natural a quem se referem os dados pessoais que são objeto de tratamento.

Sarlet, Marinoni e Mitidiero (2019, p. 482-483) afirmam que a proteção de dados pessoais alcançou uma dimensão sem precedentes no âmbito da sociedade tecnológica, de modo que, ainda que não se limite aos dados armazenados, processados e transmitidos em banco de dados, ela alcança a proteção de qualquer dado pessoal. Isso porque a facilidade de acesso aos dados pessoais e à sua velocidade potencializa a afetação de direitos fundamentais.

Ademais, a LGPD indica a boa-fé como princípio no tratamento de dados pessoais e também os seguintes princípios: finalidade, adequação, necessidade, livre acesso, qualidade, transparência, segurança, prevenção, não discriminação, responsabilização e prestação de contas.

A boa-fé, baseada na eticidade, cláusula aberta que alterou a posição positivista do direito, constante no art. 422 do Código Civil, determina que: "os contratantes são obrigados a guardar, assim na conclusão do contrato, como em sua execução, os princípios de probidade e boa-fé" (BRASIL, 2002). Além disso, exige especialmente que a hermenêutica das leis e dos contratos não seja abstrata, mas concreta, pela sua função social.

Portanto, até este ponto, conclui-se que os fundamentos dispostos na Lei Geral de Proteção de Dados Pessoais, de maneira sistemática, ainda que com início parcial de sua vigência postergado, correspondem aos valores constitucionais, que servem de parâmetros hermenêuticos na aplicação do direito, e para a ciência jurídica, que busca caminhos e soluções sistemáticas, para causar a menor perturbação social possível.

Além dos fundamentos axiológicos, a Lei 13.709/18 traz um rol de princípios vigentes que conferem garantias ao ambiente da proteção de dados pessoais ao seu titular, notadamente no que se refere aos dados sensíveis. Assim, há a declaração de direitos 
elencados na Lei Geral de Proteção de Dados Pessoais que protegem o titular dos dados pessoais no âmbito da saúde suplementar em tempos de pandemia.

Porém, o que os estudos indicam é que não basta um catálogo e um rol de direitos declarados em tantos documentos, tanto internacionais quanto brasileiros, para o longo e árduo caminho na busca da efetiva concretização desses direitos.

\subsection{Os desafios da saúde suplementar e da proteção de dados pessoais à luz da LGPD em tempos de pandemia.}

Para se analisar ainda que de forma breve os desafios da saúde suplementar e da proteção de dados pessoais à luz da LGPD em tempos de pandemia, cumpre registrar algumas linhas sobre o sistema jurídico de proteção.

\subsubsection{O SISTEMA JURÍDICO DE PROTEÇÃO}

Com a finalidade de se compreender o instituto da proteção mister um breve apontamento sobre o significado de desproteção. Desproteção significa falta de proteção, abandono, desamparo, desfavor ou a incapacidade de ser sujeito de direitos individual ou coletivamente. Nessa medida, a desproteção do Estado causa vulnerabilidade ao seu destinatário.

Kimberlé Williams Crenshaw (1989), professora de Direito na Universidade da Califórnia, destacou-se com a introdução do termo "interseccionalidade" ao se referir aos "sistemas discriminatórios" ou "eixos discriminatórios". Para ela, esses sistemas se sobrepõem e se entrecruzam, criando intersecções complexas que atingem os vulneráveis.

Importante destacar que a vulnerabilidade pode ser constatada de forma interseccional, ou seja, uma pessoa humana pode ser ou estar vulnerável em face de várias ramificações do direito, por exemplo, estar desprotegida no que tange aos seus dados pessoais no ambiente 
da tecnologia, com violações à privacidade, bem como estar desprotegida na relação contratual de planos de prestação de serviços médicos e de saúde inseridos na saúde suplementar, com a utilização de dados emergenciais armazenados e com eventuais prejuízos durante a pandemia.

Para suprir a desproteção é que surgiram as normas protetivas de dados pessoais como a LGPD, inserida no sistema jurídico constitucional e legal de proteção dos direitos fundamentais, dos direitos do consumidor e das normas reguladoras da saúde complementar, entre tantas outras.

\subsubsection{A LGPD E A PROTEÇÃO DE DADOS PESSOAIS NO CENÁRIO DA PANDEMIA}

Percebe-se, como senso comum, que a pandemia acelerou exponencialmente o uso da tecnologia da nova era digital, de maneira global, em quase todas as áreas de conhecimento e no direito, notadamente nos contratos: contratos do consumidor, contratos de planos de prestação de serviços médicos e de saúde da saúde suplementar, contratos individuais de trabalho, com o incremento do teletrabalho.

Esse uso acelerado da tecnologia aumentou a possibilidade de armazenamento de dados pessoais. Trata-se de uma nova forma de negócio monopolizado, na maioria das vezes, por multinacionais privadas que visam ao lucro e tornam os dados pessoais uma commodity. Como afirma John Perry Barlow, um dos fundadores da Electronic Frontier Foundation, the new consumer is the product itself (EFF, 2020).

Com a utilização dos dados pessoais pela tecnologia, as pessoas humanas tornam-se previsíveis, por seu comportamento na rede digital, chegando-se à possível imortalidade da personalidade digital, uma vez que após o óbito de seu titular seus dados continuam disponíveis ao acesso. Isso facilita as vendas, a publicidade das 
empresas e, por outro lado, permite a seleção e a discriminação de clientes e de beneficiários de planos de saúde. $\mathrm{O}$ uso desses dados pode desequilibrar as relações consumeristas gerando uma assimetria informacional.

O uso desmedido de dados pessoais também coloca em risco a segurança digital em tempos de pandemia. Crianças estudando em cursos à distância; câmeras abertas; trabalhadores em teletrabalho em suas casas; consumidores acessando bens e serviços de forma virtual e, no que se refere à vida e à saúde das pessoas humanas, com cruzamento de dados sensíveis de titulares para a contenção, a prevenção e o tratamento da pandemia.

É interessante assinalar que essas formas de comunicação digital podem desencadear condutas danosas aos usuários, "que são causadas por pessoas que, talvez pelo fato de sentirem uma falsa sensação de anonimato, não observam a responsabilidade por seus atos e tampouco observam preceitos éticos minimamente aceitáveis para a boa convivência na Rede" (LIBEL WALDMAN; NOGUEIRA NEVES, 2020, p. 01-28).

Informações da agência das Nações Unidas (ONU, 2020a) apontam que usuários da internet têm dados desprotegidos em um terço dos países e que as lacunas na adoção de leis de internet deixam consumidores vulneráveis, ao acessarem bens e serviços online durante a crise do COVID-19.

Diante do quadro de anormalidade conferido pela pandemia, denotam-se algumas mudanças que podem estar interferindo na proteção de dados pessoais, como por exemplo, as normas temporárias e emergenciais que prorrogam, ainda que parcialmente, o início da vigência da LGPD.

Uma das alterações normativas da Lei Geral de Proteção de Dados Pessoais, como efeito da pandemia, deriva da Medida Provisória n. 959, de 29 de abril de 2020, que estabelece a operacionalização do pagamento do benefício emergencial de preservação do emprego e da renda e do benefício emergencial mensal, 
Os Desafios Da Saúde Suplementar E Da Proteção De Dados Pessoais À Luz Da...

de que trata a MP 936/20, e prorroga a vacatio legis da Lei 13.709/18, que dispõe sobre a LGPD.

O artigo $4^{\circ}$, da Medida Provisória 959/20, determina que o art. 65, da Lei Geral de Proteção de Dados Pessoais LGPD, passe a vigorar com as seguintes alterações: "II - em 3 de maio de 2021, quanto aos demais artigos”. Significa dizer que os artigos que não são tratados nas legislações a seguir entram em vigor em 3 de maio de 2021, de forma que a entrada em vigor da LGPD tornou-se escalonada e ainda está sendo alterada neste cenário de pandemia.

As seguintes leis alteram a data de entrada em vigor da LGPD: a Lei 13.853/19, que alterou a Lei $13.709 / 18$, para dispor sobre a proteção de dados pessoais e a criação da Autoridade Nacional de Proteção de Dados, bem como os artigos constantes na Lei 14.010/20, que dispõe sobre o Regime Jurídico Emergencial e Transitório das relações jurídicas de Direito Privado (RJET), no período da pandemia do coronavírus Covid-19, e tratam das sanções previstas nos arts. 52, 53 e 54 da LGPD.

A Lei 14.010/20 prevê a entrada em vigor, em 01/08/21, das sanções administrativas previstas na LGPD, dirigidas aos agentes de tratamento de dados, em razão das infrações cometidas nas normas previstas na LGPD, ficando sujeitos às sanções aplicáveis pela autoridade nacional. Essa prorrogação visa à ampliação de tempo para que as empresas possam se adequar às normas da LGPD, durante a pandemia.

Entretanto, é bom lembrar que adiamento do início de vigência para os demais artigos, determinado pela Medida Provisória 959/20, para a data de 3 de maio de 2021, dependerá de lei para iluminar a insegurança jurídica disposta no ordenamento jurídico até o presente momento, em tempos de pandemia.

A insegurança jurídica relacionada ao início da vigência da LGPD, iniciada antes da pandemia, mas potencializada no cenário do COVID-19, pode trazer prejuízos ao Brasil especialmente no cenário internacional, pois, como já afirmado anteriormente, com a adoção da 
legislação protetiva de dados pessoais alinhadas às Diretrizes da OCDE de proteção de privacidade e de fluxo informacional de dados pessoais, o Brasil poderia ingressar na Organização para a Cooperação e Desenvolvimento Econômico (OCDE).

\subsubsection{A SAÚDE SUPLEMENTAR E A PROTEÇÃO DE DADOS PESSOAIS À LUZ DA LGPD EM TEMPOS DE PANDEMIA}

A Constituição Federal de 1988 desenhou um sistema de seguridade social que possui três subsistemas: a saúde, a assistência social e a previdência social, esta última subdivida em regime de previdência próprio dos servidores públicos e regime de previdência geral destinado aos trabalhadores em geral, nos termos da Lei 8212/91, como também pela previdência privada.

A saúde tratada nesse subsistema refere-se à saúde pública, disposta no art. 196 da Carta de 1988: "a saúde é direito de todos e dever do Estado, garantido mediante políticas sociais e econômicas que visem à redução do risco de doença e de outros agravos e ao acesso universal e igualitário às ações e serviços para sua promoção, proteção e recuperação" (BRASIL, 1988).

Nos termos do art. 199 da CF/88, "a assistência à saúde é livre à iniciativa privada" e "as instituições privadas poderão participar de forma complementar do sistema único de saúde, segundo diretrizes deste, mediante contrato de direito público ou convênio [...]" (BRASIL, 1988). A partir das diretrizes constitucionais, foi editada a Lei 9.656 , de 3 de junho de 1998, que dispõe sobre os planos e seguros privados de assistência à saúde.

Submetem-se a essa lei as pessoas jurídicas de direito privado que operam planos de assistência à saúde, sem prejuízo do cumprimento da legislação específica que rege sua atividade, adotando-se, para fins das normas estabelecidas, as seguintes definições: plano privado de assistência à saúde é "prestação continuada de serviços ou cobertura de custos assistenciais a preço pré ou pós-estabelecido, por prazo indeterminado, com a finalidade de 
Os Desafios Da Saúde Suplementar E Da Proteção De Dados Pessoais À Luz Da...

garantir, sem limite financeiro, a assistência à saúde [...]" (art. $1^{\mathrm{o}}$, inciso I, da Lei 9.656/1998) (BRASIL, 1998).

Nessa medida, o contrato de um plano privado de assistência à saúde corresponde à contratação de uma prestação continuada de serviços ou cobertura de assistência médico-hospitalar, por prazo indeterminado.

Contudo, surgiram muitos conflitos consumeristas, acerca de limitações impostas contratualmente pelas operadoras de planos de assistência à saúde, o que culminou notadamente com a criação da Agência Nacional de Saúde Suplementar (ANS), pela edição da Lei n. 9.961, de 28 de janeiro de 2000.

A ANS, nos termos do art. $3^{\circ}$-A da Lei $n^{0}$ 9.961/oo, tem a finalidade de "promover a defesa do interesse público na assistência suplementar à saúde, regulando as operadoras setoriais, inclusive quanto às suas relações com prestadores e consumidores, contribuindo para o desenvolvimento das ações de saúde no País”.

De fato, a criação da ANS trouxe avanços nas relações contratuais e nos contratos de planos privados de assistência à saúde, com mais fiscalização, e com mais garantias às partes mais vulneráveis, apesar de haver controvérsias sobre a influência das empresas de planos de saúde na indicação de diretores para a Agência Nacional de Saúde Suplementar.

No que se refere à saúde suplementar e à proteção de dados pessoais à luz da LGPD em tempos de pandemia, a ANS publicou a Nota Técnica $n^{0}$ 3/2019/GEPIN/DIRAD-DIDES/DIDES que aborda notadamente a proteção de dados no Brasil e também temas como os direitos dos titulares e as obrigações dos controladores.

Segundo a Nota Técnica supracitada, a Agência Nacional de Saúde Suplementar ANS vem implementando medidas e estratégias de gestão da informação, orientadas pelos princípios, pelas diretrizes e pelos preceitos estabelecidos nos principais marcos legais promulgados nos últimos anos, que tratam da proteção de dados pessoais. 
A Nota Técnica $n^{0}$ 3/2019/GEPIN/DIRAD-DIDES/DIDES da ANS apresenta os requisitos para aplicação da LGPD na saúde suplementar. Para que as instituições estejam aptas ao cumprimento da LGPD, a partir de sua vigência, são necessários requisitos de ordem organizacional e tecnológicos (ANS, 2019).

Entre as etapas a serem implementadas pelo Plano de Ação desenhado pelo Gartner Research, o roteiro estratégico de 2019 para networking, constam: a organização e a comunicação; os processos; os direitos do titular; a gestão do consentimento; a retenção de dados e o backup; os contratos e o plano de resposta à violação de dados (GARTNER, 2019).

O Plano de Ação para as obrigações do regulado tem o objetivo de promover as adequações necessárias das regras de envio de informações obrigatórias para a ANS para atender aos requisitos da LGPD.

Assim, além dos fundamentos constantes na LGPD, para a proteção de dados pessoais dos titulares, as normas regulamentadoras da saúde suplementar pela ANS estão procurando se adequar à efetivação dessa proteção de dados, ainda que em tempos de pandemia.

\subsubsection{OS DESAFIOS DA SAÚDE SUPLEMENTAR E DA PROTEÇÃO DE DADOS PESSOAIS À LUZ DA LGPD EM TEMPOS DE PANDEMIA}

Apesar da existência do arcabouço normativo para a proteção de dados pessoais constantes especialmente na LGPD, há desafios da saúde suplementar em tempos de pandemia.

Importante apontar que as relações jurídicas, de uma forma geral, foram abaladas e a sociedade se deparou com novos desafios e com novas questões transnacionais, as quais podem trazer, em alguma medida, impactos em várias áreas do conhecimento.

Um desses impactos pode repercutir na proteção de dados pessoais sensíveis do titular, com o cruzamento de dados pessoais para o combate, a prevenção e o tratamento da COVID-19, o que pode 
Os Desafios Da Saúde Suplementar E Da Proteção De Dados Pessoais À Luz Da...

culminar com a desproteção de dados pessoais dos titulares na LGPD, para a saúde suplementar e para os contratos de planos de prestação de serviços médicos e de saúde, com desequilíbrio dessa relação jurídica.

Devido à pandemia, os governos em todo o globo terrestre estão tomando medidas emergenciais, como políticas públicas de controle e prevenção, por motivos sanitários relacionados aos riscos de contaminação e disseminação do coronavírus SARS-CoV-2, causador da COVID-19.

Dentre as várias medidas tomadas, citam-se a medição de temperatura das pessoas nos locais de acesso ao público e o monitoramento dos governos, em parceria com empresas privadas de telecomunicações, com equipamentos de geolocalização dos usuários do serviço prestado por essas empresas.

Sobre esse tópico, Rodrigo Murtinho, diretor do Instituto de Comunicação, Informação e Tecnologia da Fundação Oswaldo Cruz, alega que há falsa dicotomia entre o monitoramento em relação à saúde e à privacidade, mas é preciso ter cuidado, uma vez que é possível monitorar a saúde da população através de registros e cruzamentos de diferentes dados, sem necessariamente expor a privacidade dos cidadãos (FAPERJ, 2020).

Interessante frisar que é possível perceber que "o tratamento dos dados pessoais está sendo utilizado para geolocalização, identificação e rastreamento de pacientes, gerenciamento do risco de contágio, entre outras atividades, com a finalidade de melhorar os instrumentos de combate à pandemia" (MODESTO; EHRHARDT JÚNIOR; SILVA, 2020, p. 250-284).

As plataformas e painéis que manipulam as informações para a tomada de decisões se utilizam de dados secundários, anonimizados. Contudo, há a possibilidade de violações à privacidade no tratamento desses dados. Ao redor do globo terrestre, já há sinais de alterações nos sistemas de monitoramento da população. 
Cingapura acabou de lançar um aplicativo para smartfone de rastreamento de contatos, para permitir às autoridades identificar aqueles que foram expostos a pessoas infectadas com coronavírus, como parte dos esforços para conter a propagação da doença. $\mathrm{O}$ aplicativo TraceTogether funcionará trocando sinais Bluetooth de curta distância entre os telefones para detectar outros usuários participantes, próximos a dois metros de distância. Ademais, os registros serão armazenados localmente em cada telefone com o aplicativo, desenvolvido pela Agência de Tecnologia do Governo de Cingapura GovTech e pelo Ministério da Saúde (EL PAIS, 2020).

Cingapura ganhou elogios internacionais por sua abordagem meticulosa no combate ao vírus, uma vez que os usuários precisarão enviar seus registros quando solicitados pelo Ministério da Saúde, que de outra forma não terá nenhum conhecimento dos dados.

Em verdade, a necessidade de consentimento para o tratamento de dados pessoais é um item importante e deve ser observado, conforme consta nos artigos $7^{\circ}$ e $8^{\circ}$ da LGPD: o tratamento de dados pessoais somente poderá ser realizado nas seguintes hipóteses, entre elas, mediante o fornecimento de consentimento pelo titular, que deverá ser prestado por escrito ou por outro meio que demonstre a manifestação de vontade do titular. De igual maneira, o consentimento é um dos requisitos para o tratamento de dados pessoais sensíveis.

Depreende-se que o consentimento está inserido na privacidade, considerada uma "porta de entrada" para reforçar outros direitos, tanto no ambiente digital quanto fora dele. $\mathrm{O}$ consentimento de titular permite a proteção contra interferências não autorizadas na vida das pessoas e indica como interagir com o mundo, estabelecendo fronteiras para limitar quem tem acesso aos corpos, lugares, coisas e informações pessoais (ONU, 2020).

A LGPD, contudo, autoriza exceções ao consentimento do titular. O compartilhamento poderá comportar exceções, sem fornecimento de consentimento do titular, nas hipóteses previstas pelo art. 11, inciso II, da lei supracitada, como em circunstâncias em que for indispensável para cumprimento de obrigação legal ou regulatória 
Os Desafios Da Saúde Suplementar E Da Proteção De Dados Pessoais À Luz Da...

pelo controlador e para tratamento de dados para execução de políticas públicas pela administração pública.

Também é possível compartilhamento de dados sensíveis sem consentimento do titular para realização de estudos por órgão de pesquisa, para proteção da vida ou da incolumidade física e para a tutela da saúde.

De outro giro, é vedada a comunicação ou o uso compartilhado de dados pessoais sensíveis para a área de saúde, com o objetivo de obter vantagem econômica, com outras exceções, nas hipóteses de prestação de serviços de saúde, de assistência farmacêutica e de assistência à saúde.

Nesses casos, é permitida a portabilidade de dados, quando solicitada pelo titular, nas transações financeiras e administrativas desses serviços, sendo vedado às operadoras de planos privados de assistência à saúde o tratamento de dados de saúde para a prática de seleção de riscos na contratação de qualquer modalidade, assim como na contratação e exclusão de beneficiários.

Cumpre sublinhar que, apesar de a Lei Geral de Proteção de Dados Pessoais ser expressa quanto a alguns direitos do titular de dados pessoais e de dados pessoais sensíveis, o contexto da sociedade da informação e de sua nova era digital traz riscos inerentes às atividades tecnológicas, as quais somente serão descortinadas após um período de tempo razoável.

Exemplo disso pode ser observado na manipulação de dados anônimos, com a possibilidade de cruzamento com outros bilhões de dados, também supostamente em anonimato, nos moldes do Bigdata, cujas repercussões ainda são desconhecidas e que, portanto, podem não estar abrangidas pela LGPD.

Diante do cenário da pandemia, importante a análise da desproteção de dados pessoais dos titulares na LGPD, para a saúde suplementar e para os contratos de planos de prestação de serviços médicos e de saúde, com possível desequilíbrio dessa relação jurídica, em tempos de pandemia. 
A Lei $13.979 / 20$ tratou das medidas de enfrentamento da pandemia e permitiu o compartilhamento de dados pessoais de pessoas infectadas, com órgãos públicos de saúde, e determinou a obrigatoriedade de seu compartilhamento entre os órgãos e entes federados de dados essenciais à identificação de pessoas infectadas ou com suspeita de infecção, com a finalidade exclusiva de evitar a sua propagação.

É bom lembrar que a Lei 13.979/20 é emergencial, portanto, tem vigência temporária e foi editada exclusivamente para as medidas de enfrentamento da pandemia decorrente do COVID-19.

Porém, também é salutar sublinhar que todos os dados coletados poderão ficar armazenados e, por questões ainda desconhecidas por esta Sociedade da Informação, especialmente no que se refere aos limites do cruzamento de dados, poderão ser ainda utilizados e manipulados com tantos outros dados, por intermédio de logaritmos, cujos interesses podem ser prejudiciais ao titular, com a desproteção de dados pessoais dos titulares, para a saúde suplementar e para os contratos de planos de prestação de serviços médicos e de saúde, com desequilíbrio dessa relação jurídica, em tempos de pandemia.

Conclui-se do exposto que o cenário de pandemia pode ter antecipado a necessidade de os atores da saúde suplementar iniciarem um Plano de Ação para as obrigações dos regulados, cujo objetivo é promover as adequações necessárias das regras de envio de informações obrigatórias para a ANS, para atender aos requisitos da LGPD, ainda que o início de sua vigência tenha sido postergado.

\section{CONSIDERAÇÕES FINAIS}

Em virtude dessas considerações, conclui-se que o cenário de crise em tempos de eventos inesperados e de grande impacto social, como a pandemia, demanda do direito tutelas jurídicas extraordinárias. Para se analisar os desafios da saúde suplementar e 
Os Desafios Da Saúde Suplementar E Da Proteção De Dados Pessoais À Luz Da...

da proteção de dados pessoais à luz da LGPD em tempos de pandemia foram abordados o cenário de pandemia decorrente do COVID-19 e a Sociedade da Informação.

Foi possível apurar também que os problemas sociais, entre eles, a necessidade de regulamentação da proteção de dados pessoais nos contratos já estava sendo analisada pela ciência jurídica e regulamentada pelos entes competentes, com alguns avanços legislativos, tanto no cenário mundial, quanto no Brasil.

Impende observar também que o que a pandemia trouxe de novo foi o agravamento de forma exponencial dos problemas já existentes na sociedade, notadamente na sociedade da informação, que pode trazer novos desafios da saúde suplementar e da proteção de dados pessoais à luz da LGPD em tempos de pandemia.

Não se pode perder de vista que a edição da Lei Geral de Proteção de Dados Pessoais permitiu ao Brasil ingressar entre os países que já adotavam legislações específicas de proteção de dados de seus cidadãos.

É interessante assinalar que os fundamentos legais correspondem às determinações constitucionais brasileiras sobre os direitos e as garantias fundamentais da pessoa humana, os quais se alinham aos termos da Declaração Universal de Direitos Humanos, de 1948. Ademais, a proteção de dados pessoais foi consagrada como direito fundamental na Carta de Direitos Fundamentais da União Europeia. Por fim, o Senado Federal brasileiro aprovou o encaminhamento de proposta de emenda constitucional, a PEC 17/2109, estabelecendo a proteção de dados como direito fundamental.

Diante do quadro de anormalidade conferido pela pandemia, denotam-se algumas mudanças que podem estar interferindo na proteção de dados pessoais, como por exemplo, as normas temporárias e emergenciais que prorrogam, ainda que parcialmente, o início da vigência da LGPD. 
Em face de todo o exposto, conclui-se que o cenário de pandemia pode ter antecipado a necessidade de os atores da saúde suplementar iniciarem um Plano de Ação para as obrigações dos regulados, cujo objetivo é promover as adequações necessárias das regras de envio de informações obrigatórias para a ANS, para atender aos requisitos da LGPD, ainda que o início de sua vigência tenha sido postergado.

Data de Submissão: 14/02/2020

Data de Aprovação: 09/06/2021

Processo de Avaliação: double blind peer review

Editor Geral: Jailton Macena de Araújo

Editor de Área: Alana Ramos Araujo

Assistente Editorial: Emylli Tavares do Nascimento

\section{REFERÊNCIAS}

AGÊNCIA BRASIL. Lei Geral de Proteção de Dados. Disponível em: https://agenciabrasil.ebc.com.br/geral/noticia/2020-04/leigeral-de-protecao-de-dados-e-adiada-para-maio-de-2021. Acesso em 11.jul.20.

ANS. AGÊNCIA NACIONAL DE SAÚDE SUPLEMENTAR. Nota

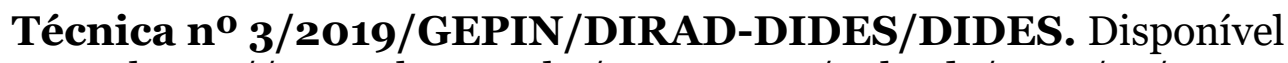
em: <https://www.sbac.org.br/wp-content/uploads/2019/12/NotaTe\%CC\%81cnica-sobre-LGPD.pdf $>$. Acesso em 02 jun.21.

BALERA, Wagner. Noções Preliminares de Direito

Previdenciário. São Paulo: Quartier Latin, 2004.

BECK, Ulrich. La sociedad del riesgo mundial: en busca de la sociedad perdida. Trad. Rosa S. Carbó. Barcelona: Paidós Ibérica, 2008.

BRASIL. Constituição Federal de 1988. Disponível em:

$<$ http://www.planalto.gov.br/ccivil_03/constituicao/constituicao.ht $\mathrm{m}>$. Acesso em 02 jun.21. 
Os Desafios Da Saúde Suplementar E Da Proteção De Dados Pessoais À Luz Da...

BRASIL. Lei 10.406, de 10 de janeiro de 2002. Institui o Código Civil. Disponível em:

<http://www.planalto.gov.br/ccivil_03/leis/2002/l10406compilada. htm $>$. Acesso em 02 jun.21.

BRASIL. Lei 9,656, de 3 de junho de 1998. Dispõe sobre os planos e seguros privados de assistência à saúde. Disponível em: <INSERIR LINK>. Acesso em 02 jun.21.

BRASIL. Lei no 12.965, de 23 de abril de 2014. Estabelece os princípios, direitos e deveres para o uso da internet no Brasil (Marco Civil da Internet). Disponível em:

http://www.planalto.gov.br/ccivil_03/_ato2011-

2014/2014/lei/l12965.htm. Acesso em: 15 mai. 2021.

BRASIL. Lei no 13.709, de 14 de agosto de 2018. Lei Geral de Proteção de Dados Pessoais (LGPD). Disponível em:

http://www.planalto.gov.br/ccivil_03/_ato2015-

2018/2018/lei/L13709.htm. Acesso em: 15 mai. 2021.

CALLEJÓN, F. B. Direito Constitucional, Pandemia e

Globalização. Prim Facie, [S. l.], v. 19, n. 42, p. 16-36, 2020. DOI: 10.22478/ufpb.1678-2593.2020v19n42.56459. Disponível em:

https://periodicos.ufpb.br/index.php/primafacie/article/view/56459 . Acesso em: 15 maio. 2021.

CANOTILHO, José Joaquim Gomes. Direito Constitucional. 6. ed. Coimbra: Almedina, 1993.

CEPAL. Pandemia de COVID-19 levará à maior contração da atividade econômica na história da região. Disponível em: https://www.cepal.org/pt-br/comunicados/pandemia-covid-19levara-maior-contracao-atividade-economica-historia-regiao-caira53. Acesso em 02.jun.21.

CNN. Disputa por material médico pode trazer consequências, diz diretor da OMC. Disponível em: https://www.cnnbrasil.com.br/business/2020/04/09/disputa-pormaterial-medico-pode-trazer-consequencias-diz-diretor-da-omc. Acesso em 02.jun.21.

COMMISSION EUROPÉENNE. Activités des Institutions Déplacements et visites. Disponível em: https://ec.europa.eu/commission/presscorner/detail/fr/CLDR o9 7. Acesso em 02.jun.21.

CRENSHAW, Kimberle. Demarginalizing the Intersection of Race and Sex: A Black Feminist Critique of Antidiscrimination Doctrine, Feminist Theory and AntiRacist Politics. The University of 
Chicago Legal Forum (8): 139-167. Chicago: University ofChicago Law School, 1989.

DIÁRIO OFICIAL DA UNIÃO DOU. Medida Provisória 959.

Disponível em:http://www.in.gov.br/web/dou/-/medida-provisorian-959-de-29-de-abril-de-2020-254499639. Acesso em 10.jul.20.

EFF. Electronic Frontier Foundation. Disponível em: https://www.eff.org/pt-br/pages/selling-wine-without-bottleseconomy-mind-global-net. Acesso em 02.jun.21.

EL PAIS. Polêmico aplicativo de rastreamento de contágios busca tirar a Europa do confinamento. Disponível em: https://brasil.elpais.com/internacional/2020-04-27/polemicoaplicativo-de-rastreamento-de-contagios-busca-tirar-a-europa-doconfinamento.html. Acesso em 02 jun.21.

ENDC. A proteção de dados pessoais nas relações de consumo: para além da informação creditícia. Disponível em: https://www.defesadoconsumidor.gov.br/images/manuais/vol 2 pr otecao de dados pessoais.pdf. Acesso em 13 ago. 2020.

FAPERJ. Uso de dados pessoais em pandemia deve ser restrito à saúde, dizem especialistas. Disponível em: http://www.faperj.br/?id=3969.2.7. Acesso em 02.jun.21.

GARTNER RESEARCH. 2019 Strategic Roadmap for Networking. Disponível em: https://www.gartner.com/en/documents/3906773/2019-strategicroadmap-for-networking. Acesso em 02.jun.21.

INTERNATIONAL MONETARY FUND. Real GPD growth. . Disponível em:

https://www.imf.org/external/datamapper/NGDP RPCH@WEO/O EMDC/ADVEC/WEOWORLD. Acesso em 09.jul.20.

JORNAL OFICIAL DAS COMINIDADES EUROPEIAS. Carta dos Direitos Fundamentais da União Europeia. Disponível em: https://www.europarl.europa.eu/charter/pdf/text pt.pdf. Acesso em 02 jun.21.

LIBEL WALDMAN, R.; NOGUEIRA NEVES, M. Sociedade Da Informação: A Responsabilidade Na Internet $\mathrm{E} O \mathrm{Mau}$ Uso Da Tecnologia, A Busca Pela Ética No Convívio Digital. Prim Facie, v. 19, n. 4O, p. 01-28, 16 abr. 2020.

MODESTO, J. A.; EHRHARDT JÚNIOR, M.; SILVA, G. B. P.. Privacidade E Tratamento De Dados Pessoais No Combate À Covid19. Prim Facie, [S. l.], v. 19, n. 42, p. 250-284, 2020. DOI: 10.22478/ufpb.1678-2593.2020v19n42.53259. Disponível em: 
Os Desafios Da Saúde Suplementar E Da Proteção De Dados Pessoais À Luz Da...

https://periodicos.ufpb.br/index.php/primafacie/article/view/53259 . Acesso em: 15 mai. 2021.

ONU. Direito à privacidade. Disponível em:

https://nacoesunidas.org/artigo-12-direito-a-privacidade/. Acesso em 03. jul. 20.

ONU. Organização Internacional do Trabalho. Disponível em: https://acoesunidas.org/agencia/oit/. Acesso em 03.jul.20.

ONU. ONU diz que usuários da internet têm dados desprotegidos em um terço dos países. 30 abr. 2020 . Disponível em:

https://news.un.org/pt/tags/dados\#: :text=ONU\%20diz\%20que\%2 ousu\%C3\%A1rios\%20da,em\%20um\%20ter\%C3\%A70\%20dos\%2opa \% $3 \%$ ADses\&text=Lacunas\%20na\%20ado\% $\mathrm{C}_{3} \% \mathrm{~A} 7 \% \mathrm{C}_{3} \% \mathrm{~A} 30 \% 20 \mathrm{de}$ \%2oleis,0\%20tema\%20ainda\%20esse\%20ano. Acesso em 02.jun.21.

ONU. Organização Mundial da Saúde declara novo coronavírus uma pandemia. 11 mar. 2020. Disponível em: https://news.un.org/pt/story/2020/03/1706881. Acesso em: 02. jun. 21.

ROUBIER, Paul. Théorie générale du droit: histoire des doctrines juridiques et philosophie des valeurs sociales. 2.ed. Paris: Librairie du Recuel Sirey, 1951.

SARLET, Ingo Wolfgang; MARINONI, Luiz Guilherme; MITIDIERO, Daniel. Curso de direito constitucional. 8. ed. São Paulo: Saraiva Educação, 2019.

WEF. World Economic Forum Annual Meeting. Disponível em: https://www.weforum.org/events/world-economic-forumannual-meeting-2011. Acesso em 02.jun.21. 


\title{
The Challenges Of Supplemental Health And Protection Of Personal Data In The Light Of LGPD In Pandemic Times
}

\author{
Denise Tanaka dos Santos
}

\begin{abstract}
The crisis scenario in times of unexpected events and of great social impact, such as the pandemic of COVID-19, demands extraordinary legal protection from the law. This work intends to identify what is available in the national legal system to face this issue, through a simple collaboration in the advancement of legal research, with implications in the resolution of this emerging issue: the challenges of supplementary health and protection of personal data in the light of the LGPD in times of pandemic. The central problem will be approached in a systematic way, based on bibliographic research. First, it was concluded that there are robust axiological prescriptions in the legal system for the protection of personal data. Second, it was concluded that the pandemic has extended the beginning of the LGPD term and, at the end, that the current pandemic scenario may, to some extend, have anticipated the adoption of a health plan. Action by supplementary health actors to adapt LGPD requirements.
\end{abstract}

Keywords: LGPD. COVID-19 pandemic. Personal data protection. Supplementary health. Information society. 